\title{
Nursing Students' Expectations and Evaluations of Mentors' Competences and Mentors' Self-Evaluations as Indicators of Mentoring Process Quality
}

\author{
Robert Lovrić, Nada Prlić, Ivana Barać, Radivoje Radić \\ Faculty of Medicine, Josip Juraj Strossmayer University of Osijek, Osijek, Croatia \\ Email address: \\ rlovric@mefos.hr (R. Lovrić) \\ ${ }^{*}$ Corresponding author \\ To cite this article: \\ Robert Lovrić, Nada Prlić, Ivana Barać, Radivoje Radić. Nursing Students' Expectations and Evaluations of Mentors' Competences and \\ Mentors' Self-Evaluations as Indicators of Mentoring Process Quality. American Journal of Nursing Science. \\ Vol. 6, No. 5, 2017, pp. 382-386. doi: 10.11648/j.ajns.20170605.12
}

Received: August 20, 2017; Accepted: September 13, 2017; Published: September 19, 2017

\begin{abstract}
Important information about the clinical education can be revealed by nursing students' initial expectations and final evaluation of mentors' competences, and mentor's self-evaluation of their competences. The aim of this study was to examine whether these constructs can be used for evaluating the atmosphere in clinical education. This was a nonexperimental prospective study. Data were collected between January and April 2012, in 12 clinics at the University Hospital Osijek. The participants were undergraduate nursing students in years 1,2 , and $3(n=150)$ and their mentors $(n=35)$ at the Faculty of Medicine, University of Osijek, during the academic year of 2012/2013. The instrument was a modified version of the questionnaire taken from The Nursing Clinical Teacher Effectiveness Inventory (NCTEI). Prior to clinical practice, the students evaluated the desirability of each competence expected from a mentor; after the clinical practice, the students estimated how often their mentor possessed and applied those competences. Mentors have evaluated their own competences according to the same items. Comparison of students' expectations and estimates shows significantly higher expectations of first and third year students $(\mathrm{p}<0.001)$. Mentors' self-assessed competences, compared to students' evaluations, were rated significantly higher by mentors of all three years $(p<0,001)$. The comparison of nursing students' initial expectations and final evaluation of mentors' competences, and mentor's self-evaluation of their competences, when they are significantly different, can provide relevant information about potential problem in clinical education.
\end{abstract}

Keywords: Nurse, Mentoring, Evaluation, Quality Indicators

\section{Introduction}

The quality of clinical practice depends on the quality of clinical teaching, which largely depends on the clinical competence of mentors [1]. Nursing mentors' competences, roles and responsibilities are described as taking responsibility for and accepting clinical education duties while providing conditions for the teaching and transfer of professional knowledge, skills and experience to establish an effective relation with the student; introducing the student to the clinical practice program; identifying possible unpredictable situations or incidents [1]; providing continuous professional support and guidance and evaluating students' competences while documenting the students' progress; encouraging students' work and ideas; building students' confidence; providing timely feedback and constructive criticism [2,3]; respecting students' uniqueness and dissimilarities [1]; using evidence-based practice [4]; serve as a role model for students in professional interaction with other health workers and with clinical facilities; taking responsibility for their own [5]. Mentors must be aware of their strong influence on students as role models because students are considerably shaped by their mentors' characteristics [6]. Mentors' competence levels will improve or hinder their students' learning [7]. Competent mentors facilitate students' acquisition of professional knowledge, 
technical, psychomotor, interpersonal and communication skills, attitudes, identity, professional responsibility, selfconfidence and independence in clinical environment [8-10]. Self-assessment is a systematic and transparent process of analysing one's own practices to improve the professional development of students, mentors, and the entire organization [11]. Effective clinical education relies on many factors, one of which will be the assessment of mentor competence. A combination of self-assessment and assessment of mentors' competences is necessary to ensure an effective clinical education [12]. This awareness helps the individual to become active and willing to introduce the required changes (i.e., to improve in personal and professional development as a mentor). Janssens Frans and Amelsvoort van Gonnie (2008) suggest that self-evaluation is a tool that ensures the quality of final outcomes [13]. The act of self-assessment is an intrinsically difficult task [12]. Mentors typically do not have all the information required to make accurate selfassessments. According to Dunning et al. (2004), many mentors underestimate or even neglect self-assessment and therefore ignore valuable information (e.g. dissonance between mentors' self-assessment and their actual level of knowledge) [14]. Consequently, they may make potentially avoidable errors [12]. Self-assessment has significant value in developing the mentors' self-reflection skills, thereby improving the quality of education [15]. Self-assessment should not imply an isolated or individualistic activity; it should commonly involve other sources of information. However, we believe that mentors' self-assessment in nursing education has not been sufficiently studied [12]. Differences between students' expectations, students' evaluations, and mentors' self-assessments indicate a lack of information exchange on each other's expectations, as well as a lack of feedback on of students' and mentors' performance $[2,3]$. These shortcomings significantly affect the final quality of interpersonal relationships and mentoring process as a whole. The aims of this study are to examine: whether there are any differences between students' expectations and assessments for each study year, during the academic year of 2012/2013 and whether there are any differences between students' assessments and mentors' self- evaluation for each study year, during the academic year of 2012/2013.

\section{Methods}

\subsection{Participants}

The participants were undergraduate nursing students in years 1,2 , and $3(n=150)$ and their mentors $(n=35)$ at the Faculty of Medicine, University of Osijek, during the academic year of 2012/2013. Mentors had the following inclusion criteria: had a bachelor's and master of science degree in nursing; were employed full time in the institutions where nursing clinical practice was performed; and had at least ten years of clinical experience in the area in which they were practicing at the time. Three courses, one for each study year, were chosen according to the following criteria: minimum 60 hours of clinical practice, minimum 9 ECTS (European Credit Transfer System) credits, and minimum 8 hours of clinical practice with mentors.

\subsection{Design}

This was a nonexperimental prospective study. Data were collected between January and April 1, 2012, in twelve clinics at the University Hospital Osijek. The clinics were teaching bases for the mentors and nursing wards for the three selected courses. During the first phase of this study, prior to conducting clinical practice, the students were surveyed by one-time application of a structured questionnaire about desirable competences that they expected of a mentor. In the second phase of the study, after each round of clinical practice with a particular mentor (five days, 30 hours), multiple application of a structured questionnaire examined students' assessments about mentors' possession and application of a specific feature of competence. In the third phase of the study, after the completion of clinical practice in their courses, a structured questionnaire was applied to test mentors' self-evaluation of their competences.

\subsection{Questionnaires}

Three versions of a questionnaire were used in the study: one for students' expectations from mentors, one for students' assessment of mentors' competences, and the third one was adapted for mentors' self-evaluation. Both students' and mentors' questionnaires were divided into two sections: the first section collected general information, and the second one consisted of 52 items representing 6 categories. Of these, 47 items were adopted from the Nursing Clinical Teacher Effectiveness Inventory (NCTEI) questionnaire, representing 5 categories: teaching ability (TA), nursing competences (NC), evaluation (EVAL), mentor-student relationship (M/S), and mentor's personality (PER) [16]. The NCTEI is a valid instrument used to evaluate mentors' competences and has been used in various studies [12, 17, 18]. The NCTEI questionnaire was translated from English to Croatian through the following steps: forward translation by 2 bilingual experts, independently; back translation, without any reference to the original instrument wording; comparison of the original and the translated items by another bilingual expert; and revision of the translated items according to the researchers' knowledge and experience [19]. Furthermore, 5 items were added to the instrument as an independent category (mentors' interaction with patients/families and the health care team). These items are explicitly defined in nursing competences in the Republic of Croatia. The aforementioned category was added because students are substantially affected by the characteristics of their mentors regarding the interaction with patients/families and the health care team. Both questionnaires were additionally tested for clarity and comprehensibility by conducting a pilot study that included 70 subjects (25 employed nurses, 25 new graduates with BSc, and 20 nursing mentors). Questionnaires were scored by one point each on the 7-point Likert scale. The 
questionnaire on students' expectations of a mentor was scored on a scale of 1 (completely unimportant) to 7 (very important), and questionnaires on students' assessment and mentors' self-evaluation were scored on a scale from 1 (never) to 7 (always). The values of Cronbach alpha coefficient showed an extremely high level of reliability of the questionnaire on students' expectations (0.94), students' assessment (0.99) and mentors' self-evaluation (0.97).

\subsection{Data Analysis}

Statistical analysis was conducted using SPSS (version 17.0 for Windows, Inc., Chicago, Illinois). Descriptive statistics for nominal variables was expressed in proportions and percentages, whereas mean and SD were used for numerical variables. Statistical significance of differences between the proportions was tested using a $\chi^{2}$-test. To compare differences between two independent groups, the Mann-Whitney U test was used. The statistical analysis of the reliability of Questionnaire was conducted using Cronbach's alpha coefficient.

\subsection{Ethical Approval}

The Ethics committee of the institution where the study was performed approved this research. All of the subjects were informed about the aim of this research in writing, and they signed an informed consent to participate in the research. The subjects' anonymity, both during and after the research, was guaranteed.

\section{Results}

The study included a total of 150 students - respondents, of which $71(47.3 \%)$ subjects in the first, $34(22.7 \%)$ in the second and $45(30 \%)$ subjects in the third study year. In terms of gender, $132(88 \%)$ respondents were women and $18(12 \%)$ men, evenly from all study years. In the first study year, there were significantly more subjects older than 25 , compared to the second and the third study year $\left(\chi^{2}\right.$ test, $\left.\mathrm{p}=0.005\right)$. There were $25(16.7 \%)$ employed respondents: 19 (26.8\%) from the first, four $(11.8 \%)$ from the second, and two $(4.4 \%)$ from the third study year $(\chi 2$ test, $\mathrm{p}=0.005)$. There were significantly more students with professional experience longer than 10 years among respondents from the first year, compared to the employed students from the second and third study year $(\chi 2$ test, $\mathrm{p}<0.001)$, where all participants had up to ten years of work experience. The study included a total of 35 female mentors - respondents, of which $10(28.6 \%)$ subjects were mentors of the first year, eight $(22.9 \%)$ of the second and 17 $(48.6 \%)$ mentors of the third study year of nursing. There were no significant differences according to age, qualifications, professional experience or participation of mentors in teaching theoretical courses. In the first study year, students' expectations of mentors' competences were significantly (extremely) higher than their students' assessments of mentors in all six categories of competences (Mann-Whitney $U$ test, $\mathrm{p}<0.001$ ) (Table 1 ). In the second year, expectations were significantly higher than the estimated mentors' competence categories in one $(\mathrm{M} / \mathrm{P} / \mathrm{HT})$ out of six categories (Mann-Whitney $U$ test, $p<0.001$ ) (Table 1). In one category (PER), students' evaluations of mentors' competences were significantly higher than their expectations (Mann-Whitney U test, $\mathrm{p}<0.001$ ) (Table 1 ). In the third study year, students' expectations were significantly higher than their evaluations of mentors' competences in five (TA, NC, EVAL, M/S, M/P/HT) out of six categories. The comparison of total students' expectations and evaluations with respect to study year, during the 2012/2013 academic year, shows significantly higher expectations of the first and third year students (Mann-Whitney U test, $p<0.001$ ), while the second year students' results show no significant difference (MannWhitney U test, $\mathrm{p}=0.055$ ) (Table 1 ).

Table 1. Differences between students' expectations and assessments of mentors' competences regarding study year in the academic year of $2012 / 2013$ (categories).

\begin{tabular}{|c|c|c|c|c|c|c|c|c|c|}
\hline \multirow{4}{*}{ Category } & \multicolumn{9}{|l|}{ Year } \\
\hline & \multicolumn{2}{|l|}{1.} & \multirow{3}{*}{$\begin{array}{l}P \\
\text { value }\end{array}$} & \multicolumn{2}{|l|}{2.} & \multirow{3}{*}{$P$ value } & \multicolumn{2}{|l|}{3.} & \multirow{3}{*}{$P$ value } \\
\hline & $\begin{array}{l}\text { Students' } \\
\text { expectations }\end{array}$ & $\begin{array}{l}\text { Students' } \\
\text { assessments }\end{array}$ & & $\begin{array}{l}\text { Students' } \\
\text { expectations }\end{array}$ & $\begin{array}{l}\text { Students' } \\
\text { assessments }\end{array}$ & & $\begin{array}{l}\text { Students' } \\
\text { assessments }\end{array}$ & $\begin{array}{l}\text { Students' } \\
\text { assessments }\end{array}$ & \\
\hline & \multicolumn{2}{|c|}{ Mean (Standard Deviation) } & & \multicolumn{2}{|c|}{ Mean (Standard Deviation) } & & \multicolumn{2}{|c|}{ Mean (Standard Deviation) } & \\
\hline Teaching Ability & $5.8(1.1)$ & $4.6(1.5)$ & $<0.001$ & $6.1(0.9)$ & $6.0(1.3)$ & 0.579 & $6.2(0.9)$ & $5.8(1.2)$ & $<0.001$ \\
\hline Nursing Competences & $5.5(1.3)$ & $4.6(1.5)$ & $<0.001$ & $6.0(1.1)$ & $6.0(1.3)$ & 0.157 & $6.1(0.9)$ & $5.5(1.3)$ & $<0.001$ \\
\hline Evaluation & $6.0(0.9)$ & $5.0(1.4)$ & $<0.001$ & $6.4(0.8)$ & $6.2(1.1)$ & 0.939 & $6.3(0.7)$ & $5.8(1.2)$ & $<0.001$ \\
\hline $\begin{array}{l}\text { Mentor / Patients / } \\
\text { Health Team }\end{array}$ & $5.9(0.9)$ & $4.5(1.6)$ & $<0.001$ & $6.3(0.8)$ & $5.6(1.7)$ & $<0.001$ & $6.3(0.7)$ & $5.8(1.2)$ & $<0.001$ \\
\hline Mentor's Personality & $5.4(1.4)$ & $5.0(1.7)$ & $<0.001$ & $5.9(1.2)$ & $6.3(1.1)$ & $<0.001$ & $6.1(0.8)$ & $5.8(1.4)$ & 0.313 \\
\hline Total & $5.7(1.2)$ & $4.7(1.5)$ & $<0.001$ & $6.2(1.0)$ & $6.1(1.3)$ & 0.055 & $6.2(0.8)$ & $5.8(1.3)$ & $<0.001$ \\
\hline
\end{tabular}

In the first and third study year, mentors' self-assessments are extremely higher than the students' estimations of mentors' competence in all six categories of competences (Mann-Whitney U test, $\mathrm{p}<0.001$ ) (Table 2). In the second study year, mentors' self-assessments are significantly higher than the students' estimations in three (TA, NC, M/P/HT) out of six categories of competences (Table 2). Mentors' selfassessed competences, compared to students' evaluations, were rated significantly (extremely) higher by mentors of all three study years in the 2012/2013 academic year (MannWhitney $U$ test, $p \leq 0,001$ ) (Table 2). 
Table 2. Differences between students' assessments and mentors' self-assessments regarding study year in the academic year of 2012/2013 (categories).

\begin{tabular}{|c|c|c|c|c|c|c|c|c|c|}
\hline \multirow{4}{*}{ Category } & \multicolumn{9}{|l|}{ Year } \\
\hline & \multicolumn{2}{|l|}{1.} & \multirow{3}{*}{$\begin{array}{l}P \\
\text { value }\end{array}$} & \multicolumn{2}{|l|}{2.} & \multirow{3}{*}{$\begin{array}{l}P \\
\text { value }\end{array}$} & \multicolumn{2}{|l|}{3.} & \multirow{3}{*}{$\begin{array}{l}P \\
\text { value }\end{array}$} \\
\hline & $\begin{array}{l}\text { Students' } \\
\text { assessments }\end{array}$ & $\begin{array}{l}\text { Mentors' } \\
\text { self- } \\
\text { assessments }\end{array}$ & & $\begin{array}{l}\text { Students' } \\
\text { assessments }\end{array}$ & $\begin{array}{l}\text { Mentors' } \\
\text { self- } \\
\text { assessments }\end{array}$ & & $\begin{array}{l}\text { Students' } \\
\text { assessments }\end{array}$ & $\begin{array}{l}\text { Mentors' } \\
\text { self- } \\
\text { assessments }\end{array}$ & \\
\hline & \multicolumn{2}{|c|}{ Mean (Standard Deviation) } & & \multicolumn{2}{|c|}{ Mean (Standard Deviation) } & & \multicolumn{2}{|c|}{ Mean (Standard Deviation) } & \\
\hline Teaching Ability & $4.6(1.5)$ & $6.0(0.9)$ & $<0.001$ & $6.0(1.3)$ & $6.4(0.8)$ & 0.004 & $5.8(1.2)$ & $6.7(0.6)$ & $<0.001$ \\
\hline Nursing Competences & $4.6(1.5)$ & $5.8(0.9)$ & $<0.001$ & $6.0(1.3)$ & $6.3(0.9)$ & 0.351 & $5.5(1.3)$ & $6.6(0.7)$ & $<0.001$ \\
\hline Evaluation & $5.0(1.4)$ & $6.0(1.0)$ & $<0.001$ & $6.2(1.1)$ & $6.4(0.9)$ & 0.537 & $5.8(1.2)$ & $6.6(1.0)$ & $<0.001$ \\
\hline Mentor / Student & $5.0(1.4)$ & $6.2(0.9)$ & $<0.001$ & $6.4(1.0)$ & $6.8(0.4)$ & 0.127 & $6.0(1.2)$ & $6.9(0.5)$ & $<0.001$ \\
\hline $\begin{array}{l}\text { Mentor / Patients / } \\
\text { Health Team }\end{array}$ & $4.5(1.6)$ & $5.7(1.1)$ & $<0.001$ & $5.6(1.7)$ & $6.5(0.8)$ & 0.013 & $5.8(1.2)$ & $6.7(0.8)$ & $<0.001$ \\
\hline Mentor's Personality & $5.0(1.7)$ & $5.9(0.9)$ & $<0.001$ & $6.3(1.1)$ & $6.2(1.0)$ & 0.217 & $5.8(1.4)$ & $6.6(0.8)$ & $<0.001$ \\
\hline Total & $4.7(1.5)$ & $5.9(1.0)$ & $<0.001$ & $6.1(1.3)$ & $6.3(0.9)$ & 0.001 & $5.8(1.3)$ & $6.7(0.7)$ & $<0.001$ \\
\hline
\end{tabular}

\section{Discussion}

According to mean values of the assessed competence categories compared to the expectations of the first-year students, mentors significantly lack in possessing and applying their competences of interpersonal relationship with the patient and the health care team, their pedagogical and professional competences, as well as their evaluation competence, their relationship with students and their selfcompetence. The reason for significantly low estimates of all these mentors' competences, regardless of the low students' expectations, may be in mentors' aggravating work conditions during the mentoring process $[1,12,20]$. According to estimates by the second-year students, mentors possess and apply their competences of positive relationship with the patient and the health care team in a significantly lesser extent, for which the students had very high expectations. These results are in line with studies that emphasize the importance of good interpersonal relationships even more than students do in their expectations in clinical practice $[5,7,21,22]$. Mentors owned and applied the competences that relate to their personality in a much larger extent than in the students' expectations, which is consistent with the results of other studies $[1,18]$. The results of students' expectations and estimates for the remaining categories and the overall level (mean values) are approximately same. This indicates that the mentors meet the expectations of students, regardless of the high initial students' expectations. According to evaluations by the thirdyear students, mentors possess and apply their pedagogical and professional competences, as well as their evaluation competence and their competence of positive relationship with the student, patient and health care team in a significantly lesser extent than expected, which is contrary to the results of other study [21]. According to total and mean values of self-evaluated competence categories, compared to the assessment of the first-year students, mentors have significantly overestimated their own competences in all six categories. The biggest difference is between evaluation and self-evaluation in the category of TA, which can be influenced by students' freshly finished high school education and the new strict didactic forms of study, when students understand the mentor as a teacher $[1,12]$. According to the total mean and median values of selfevaluated competence categories compared to the assessment of the second-year students, mentors have significantly overestimated their own competences in three (TA, NC, $\mathrm{M} / \mathrm{P} / \mathrm{HT}$ ) out of six categories. That is, matching up to the students' assessments, mentors of the second-year students defined what values they applied the most or least frequently, but they significantly overestimated how often they really do or do not apply them. The comparison of evaluated and selfevaluated mean scores of characteristics and categories does not point out mentors' overestimation; which means that mentors of the second year, compared to the mentors of the first and third year were "modest", i.e., the most objective, according to their self-assessments. These facts emphasize the importance of the quality mentor-student relationship as the foundation of effective mentoring process [7, 12, 21, 22]. According to total mean values of the category of mentors' self-evaluated competences in relation to the assessments of the third-year students, mentors have significantly overestimated their competences in all six categories. Extreme differences between self-evaluations and evaluations can be attributed to difficulties during the mentoring process. Mentors and students do not spend enough quality time in mutually respecting and caring relationship, which is a necessary mentors' competence during the mentoring process $[1,5,12]$. Lack of information exchange during the mentoring process can lead to unwanted errors and the consequences that could be avoided [7].

\section{Conclusions}

Based on the conducted research we can conclude that the estimated mentors' competences were rated significantly lower than the mentors' expected competences by the first and third year students. The mentors received the best evaluations from second-year students whose evaluations were approximately in accordance with their expectations. Mentors' self-estimated competences in performing clinical practice, compared to students' evaluations, were rated significantly higher by mentors of all three years. The mentioned significant differences between student 
expectations and assessments and mentors' self-assessments indicate the evident existence of specific problems in students-mentors interaction in the mentoring process. We intend to further examine the specificity and causes of the above problems as well as methods for improving, by combining quantitative and qualitative research methods. The results of the future study would ensure mutual feedback and provide help to the mentors and students in the clinical education. If the research is continually continued, it could be a powerful instrument to improve the quality of mentoring process.

Hence, continuing research of students' expectations and assessments as well as self-assessment of mentors' own competences can significantly change and improve the scientific and socio-educational dimension of the quality of clinical education in health care.

\section{References}

[1] Lovrić R, Prlić N, Barać I, Plužarić J, Pušeljić S, Berecki I et al. Specificities and differences in nursing students' perceptions of nursing clinical faculties' competences. Journal of Professional Nursing. 2014; 30 (5): 406-17.

[2] Agius NM, Wilkinson A. Students' and teachers' views of written feedback at undergraduate level: A literature review. Nurse Education Today. 2014; 34 (4): 552-59.

[3] Powell NJ, Rubenstein C, Sawin EM. Annan S. Student evaluations of teaching tools: a qualitative examination of student perceptions. Nurse Educator. 2014; 39 (6), 274-79.

[4] Scurlock-Evans L, Upton P, Rouse J, Upton D. To embed or not to embed? A longitudinal study exploring the impact of curriculum design on the evidence-based practice profiles of UK pre-registration nursing students. Nurse Education Today. 2017; 58: 12-8.

[5] Foster H, Ooms A, Marks-Maran D. Nursing students' expectations and experiences of mentorship. Nurse Education Today. 2015; 35 (1): 18-24.

[6] Aston L, Hallam P. Successful Mentoring in Nursing. Southernhay East Exeter: British Library, Learning Matters, 2011.

[7] Lovrić R, Piškorjanac S, Pekić V, Vujanić J, KramarićRatković $\mathrm{K}$ et al. Translation and validation of the clinical learning environment, supervision and nurse teacher scale $($ CLES $+T)$ in Croatian language. Nurse Education in Practice. 2016; 19: 48-53.

[8] Gregoric C, Wilson A. Informal peer mentoring in early career researchers. International Journal for Researcher Development. 2015; 6 (1): 40-56.
[9] Rosenau PA, Lisella RF, Clancy TL, Nowell LS. Developing future nurse educators through peer mentoring. Nursing: Research and Reviews. 2015; 5: 13-21.

[10] Won MR, Choi YJ. Undergraduate nursing student mentors' experiences of peer mentoring in Korea: A qualitative analysis. Nurse Educ Today. 2017; 51: 8-14.

[11] MacBeath JEC. Self-evaluation in European Schools: A Story of Change. London (United Kingdom): Routledge, 2000.

[12] Lovrić R, Prlić N, Zec D, Pušeljić S, Žvanut B. Students' Assessment and Self-assessment of Nursing Clinical Faculty Competencies: Important Feedback in Clinical Education? Nurse Educator. 2015; 40 (5): E1-E5.

[13] Janssens Frans JG, Amelsvoort van Gonnie HWCH, School selfevaluations and school inspections in Europe: an exploratory study. Studies In Educational Evaluation. 2008; 34 (1): $15-23$.

[14] Dunning D, Heath C, Suls JM. Flawed self-assessment implications for health, education, and the workplace. Psychological Science in the Public Interest. 2004; 5 (3): 69106.

[15] Reid-Searl K, Moxham L, Walker S, Happell B. Nursing students administering medication: appreciating and seeking appropriate supervision. Journal of Advance Nursing. 2010; $66(3), 532-41$.

[16] Knox JE, Mogan J. Important clinical teacher behaviours as perceived by university nursing faculty, students and graduates. Journal of Advanced Nursing. 1985; 10 (1); 25-30.

[17] Davies M, Hopkins S, Irene Lavery I et al. Guidance for Mentors of Nursing Students and Midwives. 2nd ed., London (United Kingdom): The Royal College of Nursing, 2009.

[18] Kube ML. Clinical Teaching Behaviors-The Relationship of Nursing Faculty Clinical Teaching Behaviors to Student Learning [dissertation]. College of Saint Mary; 2010.

[19] Råholm MB, Thorkildsen K, Löfmark A. Translation of the Nursing Clinical Facilitators Questionnaire (NCFQ) to Norwegian language. Nurse Education in Practice. 2010; 10 (4), 196-200.

[20] Gopee N. Mentoring and supervision in healthcare. 2nd ed. Los Angeles (United States): SAGE, 2011.

[21] Gillespie M. Student-teacher connection in clinical nursing education. Journal of Advance Nursing. 2002; 37 (6): 566-76.

[22] Bastable SB, Gramet P, Jacobs S, Sopczyk DL. Health professional as educator: principles of teaching and learning, London (United Kingdom): Jones \& Bartlett Learning LLC, 2011. 